\title{
The Nature of Anterior Negativities Caused by Misapplications of Morphological Rules
}

\author{
Andrea Krott ${ }^{1}$, R. Harald Baayen ${ }^{2,3}$, and Peter Hagoort ${ }^{4,5}$
}

\begin{abstract}
This study investigates functional interpretations of left anterior negativities (LANs), a language-related electroencephalogram effect that has been found for syntactic and morphological violations. We focus on three possible interpretations of LANs caused by the replacement of irregular affixes with regular affixes: misapplication of morphological rules, mismatch of the presented form with analogy-based expectations, and mismatch of the presented form with stored representations. Event-related brain potentials were recorded during the visual presentation of existing and novel Dutch compounds. Existing compounds contained correct or replaced interfixes (dame + $s+$ salons $>$ damessalons vs. *dame $+n+$ salons $>$ *damensalons "women's hairdresser salons"), whereas novel Dutch compounds contained interfixes that were either supported or not supported by analogy to similar existing com-
\end{abstract}

\section{INTRODUCTION}

One of the language-related event-related potential (ERP) effects that has been established for various languages is the left anterior negativity (LAN). LANs Occur between 300 and 500 msec poststimulus and show a frontal maximum, which is usually larger over the left hemisphere. The majority of studies examining LAN effects have related them to syntactic violations (see also Hagoort, Wassenaar, \& Brown, 2003; Coulson, King, \& Kutas, 1998; Friederici, Hahne, \& Mecklinger, 1996; Friederici, 1995; Münte, Heinze, \& Mangun, 1993), as they occur, for instance, for violations of word-category constraints (Friederici, Gunter, Hahne, \& Mauth, 2004; Friederici et al., 1996; Münte et al., 1993). Apart from these syntactically caused LANs, several studies reported LAN effects for the misapplication of regular morphological rules (Rodriguez-Fornells, Clahsen, Lleo, Zaake, \& Münte, 2001; Gross, Say, Kleingers, Clahsen, \& Münte,

\footnotetext{
${ }^{1}$ University of Birmingham, United Kingdom, ${ }^{2}$ Max Planck Institute for Psycholinguistics, The Netherlands, ${ }^{3}$ Radboud University Nijmegen, The Netherlands, ${ }^{4}$ F.C. Donders Center for Cognitive Neuroimaging, The Netherlands, ${ }^{5}$ Nijmegen Institute for Cognition and Information, The Netherlands
}

pounds (kruidenkelken vs. ?kruidskelken "herb chalices"); earlier studies had shown that interfixes are selected by analogy instead of rules. All compounds were presented with correct or incorrect regular plural suffixes (damessalons vs. *damessalonnen). Replacing suffixes or interfixes in existing compounds both led to increased (L)ANs between 400 and $700 \mathrm{msec}$ without any evidence for different scalp distributions for interfixes and suffixes. There was no evidence for a negativity when manipulating the analogical support for interfixes in novel compounds. Together with earlier studies, these results suggest that LANs had been caused by the mismatch of the presented forms with stored forms. We discuss these findings with respect to the single/dual-route debate of morphology and LANs found for the misapplication of syntactic rules.
1998; Penke et al., 1997; Weyerts, Penke, Dohrn, Clahsen, \& Münte, 1997).

The aim of these morphologically oriented studies was to resolve an issue that has become a matter of intense debate in psycholinguistic research, the question as to whether regular and irregular morphology are handled by one and the same cognitive system. Supporters of a dual-mechanism model assume that regular complex forms (e.g., walked) are products of symbolic rules (unifying the stem walk with a past tense morpheme -ed), whereas irregular forms (e.g., went) are stored as whole units in a memory module (e.g., Ullman, 2001, 2004; Pinker \& Ullman, 2002; Pinker, 1999). Importantly, rules and the associative memory module are assumed to have distinct neurological manifestations in the brain. In contrast, supporters of single-mechanism models, in particular of connectionist models, argue that both types of past-tense forms (regular and irregulars) are handled by only one cognitive system, an associative memory system (e.g., Seidenberg \& Joanisse, 2003; Joanisse \& Seidenberg, 1999; Rumelhart \& McClelland, 1986). Similarly, Pothos (2005) has recently argued that what has been considered as rule processes and analogy/ similarity processes in cognitive psychology are "extremes on a single continuum of similarity operations." 
Pothos proposed that rule processes are based on similarity in which only a single (abstract) feature or a small subset of features is involved, whereas analogy processes are based on a large set of features.

The debate has recently focused on an alternative explanation of why regular and irregular forms might engage different brain areas. As part of the focus on the English past tense, Joanisse and Seidenberg (1999) argued that the underlying processes of regular and irregular verbs are the same but that the production of regular verbs relies more heavily on phonological information (see also Braber, Patterson, Ellis, \& Ralph, 2005; Ralph, Braber, McClelland, \& Patterson, 2005; Bird, Ralph, Seidenberg, McClelland, \& Patterson, 2003), and the production of irregular verbs relies more heavily on semantic information because stem and past tense share a semantic representation (Patterson, Ralph, Hodges, \& McClelland, 2001). In line with a semantic difference between regulars and irregulars, Baayen and Martin (2005) showed that irregulars have a denser semantic neighborhood than regulars. On the other hand, there is evidence that the distinction between phonological and semantic processing load might not capture the whole picture. Priming studies and patient studies suggest that the relation between irregular forms and their stems is not semantic but morphological (Marslen-Wilson \& Tyler, 1998, 2003; see also Miozzo, 2003; Tyler, Randall, \& Marslen-Wilson, 2002). Furthermore, Marlsen-Wilson and Tyler (2003) and Tyler et al. (2002) argued that it is not pure phonological information that is relevant for regular verbs, but phonological parsing. This is in accordance with a study by Miozzo (2003), who tested a patient who encounters problems with phonology but not with regular verbs. Therefore, regular and irregular words might engage different brain areas because regular forms are morphophonologically complex and involve phonological parsing processes.

One of the first studies that examined ERPs to provide evidence for the dual-mechanism model presented correct and incorrect German noun plurals (Weyerts et al., 1997). Participants read sentences ending in correct or incorrect nouns that take either the regular $-s$ suffix or the irregular $-(e) n$ suffix. ${ }^{1}$ Incorrect plurals were formed by exchanging $-s$ with $-(e) n$ and vice versa. Exchanging the regular $-s$ with the irregular -en resulted in a central phasic negativity resembling an N400 effect (Kutas \& Hillyard, 1980). As N400 effects have been found for nonwords (Deacon, Dynowska, Ritter, \& Grose-Fifer, 2004; Bentin, 1987; Rugg, 1987; Rugg \& Nagy, 1987; Bentin, McCarthy, \& Wood, 1985), the authors conclude that the use of irregular suffixes created nonwords. Exchanging the irregular $-e n$ with the regular $-s$, though, led to a LAN for incorrect forms.

The basic finding of Weyerts et al. (1997) that the incorrect usage of regular affixes leads to a LAN has since been confirmed in other studies examining German, Italian, and Catalan verb forms (Rodriguez-Fornells et al., 2001; Gross et al., 1998; Penke et al., 1997). The topography of the negativity, though, varied from study to study. Although German inflections revealed a LAN with a maximal difference at the left frontal site F7, Italian verb inflections led to a widespread negativity with a slight lateralization towards the right hemisphere. Catalan stem vowel replacements elicited a left-sided negativity that spread even into posterior regions. These topographic differences not withstanding, the lack of an anterior negativity for irregular suffixes has been taken as evidence for a dual-route model, that is, for a distinction between rule processing and analogy processing.

But what exactly has caused the frontal negativity? In all studies, the effect occurred when a regular affix had been attached to an irregular stem, which is assumed to block the application of the rule. Thus, the source of LANs has been assumed to be the misapplication of rules. Furthermore, as LANs have also been found for violations of syntactic rules (Hagoort et al., 2003; Coulson et al., 1998; Friederici et al., 1996; Friederici, 1995; Münte et al., 1993; Rösler, Putz, Friederici, \& Hahne, 1993; Neville, Nicol, Barss, Forster, \& Garrett, 1991), it has been claimed that LAN effects found in sentence processing and in morphological processing are very similar, both reflecting morphosyntactic structure building (Rodriguez-Fornells et al., 2001; Gross et al., 1998; Penke et al., 1997; Weyerts et al., 1997). However, there is no consent as to the exact functional interpretation of syntactically caused LANs. It has been proposed that syntactically caused LANs are elicited by subcategorization violations or morphosyntactic violations (Friederici, 1995). This explanation accounts for the bulk of the studies that reported LANs, namely, for violations of subject-verb agreement, gender agreement, and tense (Palolahti, Leino, Jokela, Kopra, \& Paavilainen, 2005; Rossi, Gugler, Hahne, \& Friederici, 2005; Köster, Gunter, Wagner, \& Friederici, 2004; Vos, Gunter, Kolk, \& Mulder, 2001; Osterhout \& Holcomb, 1995; Münte \& Heinze, 1994). LAN effects have also been related to limitations of verbal working memory (Coulson et al., 1998; Kluender \& Kutas, 1993b; see also Vos et al., 2001) because they have been reported for manipulations that are not necessarily syntactic in nature (Kluender \& Kutas, 1993a). The latter account links LAN effects to general resource requirements and is in line with the idea that LANs are a family of effects. In order to better understand the functional source of LANs, it is important to know whether syntactically and morphologically caused LANs are indeed functionally identical. Here we will focus on the functional nature of the LAN that is observed in the context of morphological processing. We will investigate whether this LAN indeed indicates rule-based processing.

Similar to LANs elicited by syntactic rule violations, morphologically caused LANs have been claimed to be elicited by the misapplication of a morphological rule to irregular stems. If this is correct, then these LANs might 
indeed be functionally identical. Due to the type of manipulation conducted in all these studies, we can, however, see two alternative explanations. First, LANs have been elicited when presenting manipulated forms of irregular inflections but not of regular inflections. Dual-route approaches do argue that regular inflected forms are NOT stored. All parties agree that irregular inflected forms are stored in the mental lexicon. If this is the case, then the cause for the LAN might not be the misapplication of a rule, but the deviation of the manipulated form from the stored irregular form. For example, although changing the irregular stored plural Muskeln ("muscles") into the incorrect *Muskels resulted in a LAN, changing the regular plural Korsetts ("corsets"), which is not stored according to dual-route accounts, into the incorrect *Korsetten did not (examples taken from Weyerts et al., 1997). This also explains why Penke et al. (1997) did not find any differences in electroencephalogram (EEG) activations for German nonce verbs with regular versus irregular affixes because nonce verbs are not stored.

Second, LANs might result from a mismatch of the presented form with an expected form that is based on similarity (i.e., analogy to other stored forms). Note that LANs have only been observed when irregular forms were manipulated, not when regular forms were changed. Irregular forms and regular forms commonly do not only differ with respect to regularity, but also with respect to phonological similarity. Irregular inflections usually form clusters within the lexicon in terms of phonology (see, e.g., descriptions of English irregular past-tense forms in Ullman, 1999; Bybee \& Moder, 1983; Bybee \& Slobin, 1982). These clusters of similarity cause gang effects. This means that members of a cluster are protected from being regularized even if they are infrequently used (such as fling - past tense flung, which is supported by phonologically similar words such as cling, sling, slink, spin, sting, string, swing, and wring). In contrast, regular forms, such as German regular noun plurals or past tense forms of English regular verbs, although not necessarily free of similarity (Albright \& Hayes, 2003; Köpcke, 1998), lack gang effects. As a result, only the manipulation of irregular forms, not that of regular forms, in previous studies might have clashed with the analogical support that the forms received from similar stored forms. For example, in Weyerts et al. (1997), processing the German irregular nouns ending in schwa such as Algen ("seaweed") or Waisen ("orphans") might have been affected by a large number of other nouns ending in schwa that take the $-n$ plural suffix, whereas German regular nouns such as Korsetts ("corsets") and Clowns ("clowns") or the plurals of names such as Pauls or Oskars were not affected by gang effect because they do not belong to phonological clusters.

Pothos (2005) has made a similar claim when arguing that rules and analogy are extremes on a continuum of similarity, differing only in terms of the number of features involved. He assumes that more features are involved for analogy/similarity processes, which suggest that the replacement of rule-governed morphemes and analogy-governed morphemes should lead to a quantitative, but not qualitative, difference. Thus, his hypothesis predicts that rule-governed and analogy-governed morphemes elicit similar ERP effects that might differ in amplitude. ERP studies so far render this possibility rather unlikely because the replacement of regular suffixes led to ERP effects that appear to be rather qualitatively than quantitatively different. The manipulation of irregular complex forms elicited LANs, whereas the manipulation of regular complex forms led to no effect or an N400 (for German noun plurals).

In order to test the three hypotheses above for a single morphological process, we manipulated affixes that are productively used in novel combinations but that are not governed by rules: interfixes that occur in Dutch noun-noun compound words (e.g., $-s-$ in schaap $+s+k o o i$ "sheep fold" or -en- in boek + en + kast "bookcase"). Although previous studies on Dutch interfixes have shown that native speakers strongly agree on the use of interfixes in novel compounds and that it therefore should be possible to predict which interfix is the most appropriate one for a novel compound, attempts to account for interfixes by rules have been unsuccessful (Krott, Baayen, \& Schreuder, 2001; Mattens, 1984; van den Toorn, $1982 \mathrm{a}, 1982 \mathrm{~b}) .^{2}$ In contrast, paradigmatic analogy to stored exemplars has been proven to be highly predictive of the usage of interfixes in both existing and novel compounds (Krott et al., 2001). The main analogical basis appears to be the distribution of interfixes in the set of compounds that already exist in the language and that share the left constituent with the target compound, namely, the "left constituent family" (Krott, Schreuder, \& Bayen, 2002b; Krott et al., 2001). For instance, the left constituent family of the compound schaap $+s+$ hond ("sheep dog") consists of compounds such as schaap $+s+$ boofd ("sheep head"), schaap + s + leer ("sheep leather"), and schaap + $e+$ vlees ("mutton"). The analogical effect of the left constituent family has been demonstrated in several off-line and on-line production studies (e.g., Krott, Schreuder, et al., 2002b; Krott et al., 2001) and in a well-formedness decision experiment (Krott, Hagoort, \& Baayen, 2004). These studies revealed that when a novel compound had to be formed from two visually presented nouns, a particular interfix was chosen more often and faster when there was strong support for it in the left constituent family than when there was weak support. Furthermore, decisions on the well-formedness of visually presented existing and novel compounds led to more accurate and faster responses when the interfixes of the compounds were supported by the bias of the left constituent family. Apart from the dominant effect of the left constituent 
family, behavioral and simulation studies have also shown some effect of the right constituent family as well as of properties of the left constituent, such as semantic class, rhyme, and suffix (Krott, Krebbers, Schreuder, \& Baayen, 2002; Krott, Schreuder, \& Baayen, 2002a; Krott et al., 2001).

In sum, previous studies all show that analogy is a strong force for Dutch interfixes in that it can create strong expectations about which interfix should appear in a compound. Dutch interfixes therefore provide the ideal case to test all three possible causes of morphologically elicited LANs: misapplication of rules, mismatch with stored forms, and mismatch with analogy (similarity)-based expectations.

We examined ERPs during the processing of Dutch interfixes in existing compounds and novel compounds. We replaced interfixes in existing compounds (e.g., *damensalon instead of damessalon "women's hairdressing salon") and manipulated the analogical support of the left constituent family for interfixes in novel compounds (e.g., kruidenkelk "herb chalice" with support and ?kruidskelk without support). Our expectations were as follows. If it is indeed the misapplication of a rule that causes morphological anterior negativities in the ERP, then there should be no such negativity for the replacement of an interfix in an existing compound because interfixes are not governed by rules. Similarly, no such effect should be observed for the usage of an interfix without analogical support in a novel compound. If a LAN is caused by the mismatch of the presented form with a stored form, then the replacement of an interfix of an existing compound should show a LAN, whereas the usage of an interfix without analogical support in novel compounds should not show a LAN because those are not stored. Finally, if the negativity is caused by a lack of analogical support, then the usage of an interfix that is not supported by the constituent family should always cause a LAN. We therefore should find LANs for the manipulation of interfixes in both existing and novel compounds.

We presented the compounds with plural suffixes and manipulated not only the interfixes but also the correctness of the plural suffixes. This allowed us to directly compare the effect of the replacement of analogy-based interfixes with the replacement of regular affixes. The manipulation of Dutch nominal plural suffixes is most similar to the manipulation of German nominal plural suffixes in the study of Weyerts et al. (1997). Note though, that in contrast to German, Dutch has two plural suffixes that are both regular (i.e., rule-governed), namely, $-s$ and $-e n$, and their contexts are mutually exclusive. For example, the main rule of Dutch plurals states that $-s$ appears after unstressed syllables (sg. vader "father," pl. vaders "fathers"), whereas -en appears after stressed syllables (sg. trein "train," pl. treinen "treins") (for a full discussion of the suffixes' regularity and the rules that govern them, see Baayen,
Schreuder, De Jong, \& Krott, 2002). Replacing Dutch plural suffixes therefore means to exchange one regular suffix by another one and to apply an inappropriate rule (e.g., *treins instead of treinen). As the misapplication of the German plural rule had caused a LAN, we expected a similar effect when exchanging two regular suffixes if it is indeed the misapplication of a rule that leads to this negativity. If it is the mismatch with a stored form, the outcome depends on whether Dutch plural forms are stored. It is now generally assumed that at least high-frequency regularly inflected forms are likely to be stored (New, Brysbaert, Segui, Ferrand, \& Rastle, 2004; Baayen et al., 2002; Bertram, Laine, Baayen, Schreuder, \& Hyona, 2000; Alegre \& Gordon, 1999; Schreuder, de Jong, Krott, \& Baayen, 1999; Baayen, Dijkstra, \& Schreuder, 1997; Sereno \& Jongman, 1997). Thus, if the plural forms of our experimental compounds (or of the compound heads) are stored, a LAN is expected. If they are not stored, there is no mismatch and no LAN is expected. For the interpretation of our results, we have to be aware that a LAN caused by the exchange of Dutch plural suffixes might either be due to a misapplication of rules or to a mismatch with stored plural forms.

Furthermore, if rules and analogy are extremes on a continuum of similarity, differing in number of features involved as argued by Pothos (2005), then violations concerning one or few features should lead to a quantitatively reduced LAN (reduced amplitude or less spread) compared to violations concerning a large number of features. Neither of the processes investigated in this study involves a large number of features. The rule for plural suffixes involves two features: word type (noun) and stress of the final syllable. Dutch interfixes appear to involve mainly one feature, the left constituent. However, other features (i.e., the right constituent as well as semantic class, suffix, and rhyme of the final syllable of the left constituent) have been shown to play a role as well, although a minor one (Krott, Krebbers, et al., 2002; Krott, Schreuder, et al., 2002a; Krott et al., 2001). Thus, because interfixes involve a very similar number of features to plural suffixes, the effect of the similarity should also be similar if it is the lack of analogical support that causes LANs.

\section{METHODS}

\section{Materials}

The compounds for this experiment had been used in an earlier study as items for a well-formedness decision experiment (Krott et al., 2004). List A consisted of 160 existing compounds that were taken from the CELEX lexical database (Baayen, Piepenbrock, \& Gullikers, 1995). All of those contained interfixes that were supported by the left constituent family. ${ }^{3}$ Support by the constituent family was quantified as the percentage of 
family members containing the interfix of the target compound. The mean percentage of supporting family members was $98.3 \%$ (23.1 family members) with a range of $80-100 \%$ (4-200 family members; example: damessalons $<$ dame $+S+$ salon + PLURAL "women's hairdressing salons" with a bias for the $-s$-interfix). As previous studies had also found evidence for a small effect of the support of the right constituent family, it was made sure that right constituents preferred, on average, the same interfixes as the left constituents (support strength: mean $=56.5 \%$ [6.9], range $=0$ $100 \%$ [0-46]). We manipulated both the replacement of the plural suffix (correct vs. incorrect) and replacement of the interfix (correct vs. replaced), leading to the four conditions listed in Table 1 . The new interfixes of the manipulated compounds were not supported by the constituent families (new left support: mean $=0.9 \%$ $[0.2]$, range $=0-20 \%[0-8]$; new right support: mean $=$ $24.3 \%[3.1]$, range $=0-77.8 \%[0-28]$; example: $*$ damensalons $<$ dame $+N+$ salon + PLURAL "women's hairdressing salons").

In addition to these existing compounds, we also used 160 novel compounds (List B; see also Krott et al., 2004). Similar to the existing compounds, we manipulated the replacement of the plural suffix (correct vs. incorrect). In addition, we manipulated the support of the left constituent family for the interfix (with support vs. without support; see Table 1). For the interfixes with family support (e.g., kruidenkelken $<$ kruid + EN + kelk + PLURAL "herb chalices"), the mean percentage of supporting family members was $96.7 \%$ (range $=70.6-$ $100 \%)$. The mean number of such supporting compounds was 10.5 (range $=1-78$ ). The bias of the right constituent families for the chosen interfixes varied, but was neutral on average (mean support: 45.1\% [3.2 family members], range $=0-95.5 \%$ [0-90 family members $]$ ). The same compounds were also presented with inter-

Table 1. Variations of the Existing Compound Damessalons ("Women's Hairdresser Salons") and the Novel Compound Kruidenkelken ("Herb Chalices") for All Experimental Conditions

Existing compounds

Correct interfix

Correct suffix

Incorrect suffix

damessalons

*damessalonnen

Novel compounds

Interfix with support

Correct suffix

kruidenkelken

Incorrect suffix
Replaced interfix

*damensalons

*damensalonnen

Interfix without support

?kruidskelken

*kruidenkelks fixes (e.g., ?kruidskelken $<$ kruid $+S+$ kelk + PLURAL "tabacco velts") that were not supported by the left constituent family (support: mean $=1.7 \%[0.2]$, range $=$ 0-29.4\% [0-14]; support of right family: mean $=31.1 \%$ [2.6], range $=0-78.9 \%[0-22])$. The distribution of different interfix manipulations $(-s->-$ en-, - en $->$ $\left.-s_{-},-\varnothing_{-}>-s_{-},-\varnothing_{-}>-e n-,-s_{-}>-\varnothing_{-},-e_{-}>-\varnothing_{-}\right)$ was very similar for novel compounds and existing compounds. Novel and existing compounds were matched for length (existing compounds: mean $=12.2$ letters $=4.5 \mathrm{~cm}$, range $=3.2-5.4 \mathrm{~cm}$; novel compounds: mean $=12.0$ letters $=4.5 \mathrm{~cm}$, range $=3.1-5.0 \mathrm{~cm}$ ). They were also matched for frequency of the right constituents [existing compounds: 133 per million words; novel compounds: 102 per million words, $t(160)=$ $1.3, p=.202]$. However, it was not possible to match them for frequency of the left constituents [existing compounds: 211 per million words; novel compounds: 71 per million words, $t(160)=4.2, p<.001]$. Nevertheless, both types of left constituents are in the higherfrequency range.

In addition to Lists $\mathrm{A}$ and $\mathrm{B}$, there were 222 further existing Dutch compounds that served as fillers. One hundred eighty-one of those were compounds with correct interfixes and plural suffixes and increased the number of correct items; the rest had been manipulated with regards to interfixes and/or suffixes and served as targets for an experiment not reported here.

We distributed the items over four experimental lists such that each experimental list contained a compound stem only once (abstracting away from plural suffix and interfix). This ensured that no participant saw any compound stem twice. Thus, a given participant was exposed to 160 existing compounds (40 stems with correct interfix and correct suffix, 40 stems with correct interfix and incorrect suffix, 40 stems with replaced interfix and correct suffix, and 40 stems with replaced interfix and incorrect suffix), to 160 novel compound stems (40 stems with support for interfix and correct suffix, 40 stems with support for interfix and incorrect suffix, 40 stems with unsupported interfix and correct suffix, and 40 stems with unsupported interfix and incorrect suffix), and to 222 filler items. In all, a participant saw 542 trials, preceded by 25 practice items that were similar to the experimental lists, but not part of them.

\section{Participants}

Forty-two students participated in the experiment and were paid for their participation. Ten participants had to be excluded from the analysis due to a high percentage of artifacts. The remaining 32 participants (28 women) were aged between 18 and 26 years $($ mean $=22$ ). All had normal or corrected-to-normal vision and were right-handed according to an abridged Dutch version of the Oldfield Handedness Inventory (Oldfield, 1971). 
None of the participants had any known neurological impairments.

\section{Procedure}

The presentation of the stimuli was equal to that of the well-formedness decision experiment of Krott et al. (2004). The compounds were presented one at a time on a NEC Multicolor monitor in white lowercase 15-point Helvetica letters on a dark background. Viewing distance was approximately one meter and the stimuli subtended a visual angle of maximally $3.2^{\circ}$ horizontally and $0.23^{\circ}$ vertically. Each stimulus was preceded by a fixation mark that remained on the screen for $1750 \mathrm{msec}$. After another $750 \mathrm{msec}$, the Dutch definite article "de" appeared at the same position for 200 msec. The presentation of the article made sure that the compounds were processed as plural nouns instead of as verb forms. After another $200 \mathrm{msec}$, the stimulus compound appeared at the same position for $600 \mathrm{msec}$, followed by an empty screen for $1000 \mathrm{msec}$. Participants were tested in a single session while seated in an easy chair in a dimly lit noise-attenuating experimental booth. They were instructed to attentively read the words and to only blink their eyes during the presence of the fixation mark, but not when it disappeared. No other task demands were imposed to keep the task as natural as possible. The experiment lasted approximately $2 \mathrm{hr} 15 \mathrm{~min}$, including preparation and breaks.

\section{EEG Recording and Data Analysis}

Continuous EEG was recorded from 29 sintered $\mathrm{Ag} / \mathrm{AgCl}$ electrodes mounted in an electrode cap, each referred to an electrode placed at the left mastoid. An additional electrode at the right mastoid was used to check for different contributions of the experimental variables to the two mastoid sites (no differences were observed). Twenty-three electrodes (FC, FCz, Cz, Pz, Oz, AF3, AF4, F7, F8, F3, F4, FT7, FT8, FC3, FC4, C3, C4, CP3, CP4, P3, $\mathrm{P} 4, \mathrm{PO} 7, \mathrm{PO} 8)$ were placed according to the $10 \%$ standard system of the American Electrophysiological Society. An additional six electrodes were placed over nonstandard intermediate locations: LT and RT 33\% of the interaural distance lateral to Cz; LTP and RTP $30 \%$ of the interaural distance lateral to $\mathrm{Cz} ; 13 \%$ of the inion-nasion distance posterior to Cz; LP and RP midway between LTP/RTP and PO7/PO8. Vertical and horizontal eye movements were recorded by a supra- to suborbital bipolar montage and by a right-to-left canthal bipolar montage, respectively. EEG and electrooculogram (EOG) signals were amplified by a SynAmp Model 5083 EEG amplifier system, using a band-pass filter of $0.02-30 \mathrm{~Hz}$. Impedances were kept below $3 \mathrm{k} \Omega$ for EEG electrodes and below $5 \mathrm{k} \Omega$ for EOG electrodes.
Signals were digitized on-line with a sample frequency of $200 \mathrm{~Hz}$.

Single waveforms were baseline-corrected by subtracting the mean amplitude in the 150-msec interval preceding the compound noun. Waveforms were semiautomatically screened for electrode drifting, amplifier blocking, muscle artifacts, eye movements, and blinks in a window between 400 msec before (i.e., from presentation onset of determiner de) and 1200 msec after presentation onset of the compounds. Trials with artifacts were rejected for analysis (overall rejection rate $=$ $9.6 \%, S D=6.1 \%)$. Mean amplitudes were calculated for each subject, condition, and electrode.

Data were analyzed by means of repeated measures analyses of variance (ANOVAs). Based on a visual inspection of the waveforms, we selected two time windows for the analyses: 400-700 and 900-1200 msec after stimulus onset of the compounds. We split the 32 electrode sites used for EEG recording into quadrants and calculated mean amplitudes for each quadrant (anterior left [F7, FT7, AF3, F3, FC3], anterior right [F8, FT8, AF4, F4, FC4], posterior left [LTP, LP, CP3, P3, PO7], posterior right [RTP, RP, CP4, P4, PO8]). Greenhouse-Geisser corrections were applied whenever effects with more than one degree of freedom were evaluated.

Using existing and novel compounds, both with correct/incorrect suffixes, allowed us to first conduct omnibus ANOVAs to investigate the overall effect of the factors existence (words vs. nonwords) and replacement of plural suffixes (existing vs. novel). Although interfix replacement in existing compounds and manipulation of the interfix support in novel compounds appear to be similar, they are in fact substantially different. The replacement of interfixes in existing compounds creates nonwords, whereas novel compounds with interfixes that are supported or not supported by the left constituent family are both possible words. We therefore were not able to include interfix support as a factor into the omnibus analysis. Instead, we examined interfix replacement and interfix support for existing and novel compounds separately.

\section{RESULTS \\ All Compounds}

\section{Left Anterior Negativity}

An ANOVA for the 400-700 msec window with the factors suffix replacement, existence, and quadrant revealed a main effect of existence $[F(1,31)=42.4$, $p<.001]$.This result reflects a widespread and longlasting negativity for novel compounds starting at about $350 \mathrm{msec}$ (see Figure 1). In addition, there was an interaction of Suffix replacement $\times$ Quadrant $[F(3,93)=5.0$, $p=.009$, partial $\left.\eta^{2}=.138\right]$. Post hoc analyses showed a significant difference only in the left anterior quadrant $[t(31)=2.5, p=.008$, one-tailed, Bonferroni-adjusted 
Figure 1. Grand-average ERPs for a subset of nine electrodes and an isovoltage map (400-700 msec) showing a long-lasting negative shift and its scalp distribution for novel compounds compared to existing compounds. In this and all following figures, negativity is plotted upwards.

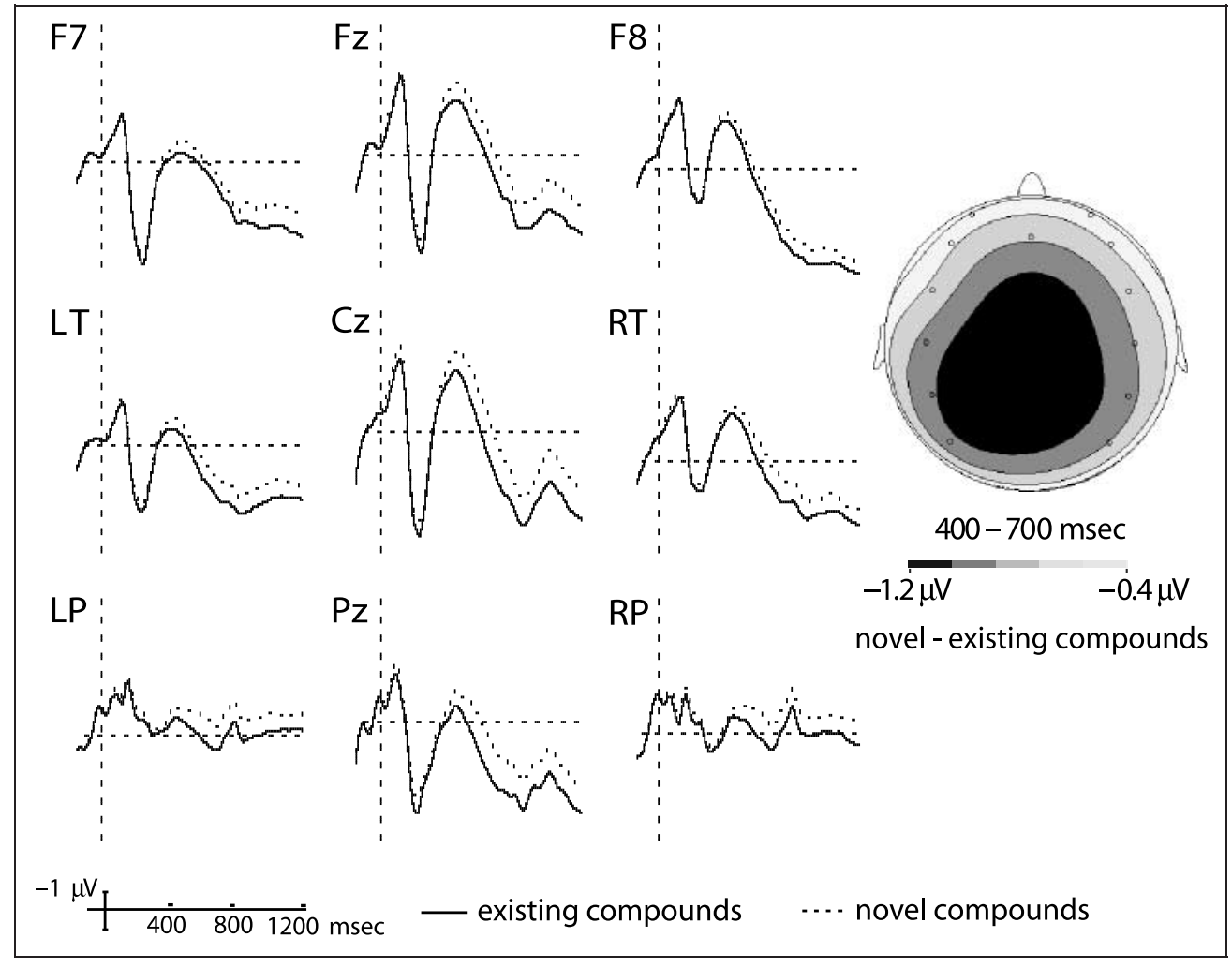

$\alpha$-level $=.0125]$, with an increased negativity for incorrect suffixes, as shown in Figures 3 and 6. All other effects of the ANOVA were not significant (all $F_{S}<1$ ). This means that the LAN caused by suffix replacement occurred for both existing and novel compounds, and the widespread negativity observed for novel compounds was independent of the negativity caused by suffix replacements. Note that the time window for the LAN is slightly later than that observed in previous studies (e.g., Coulson et al., 1998; Penke et al., 1997; Weyerts et al., 1997; Friederici, Pfeifer, \& Hahne, 1993), but it is consistent with the time window of a LAN reported for the processing of auditorily presented compounds in Köster et al. (2004). The delay is most likely due to the unusual length of compound stimuli.

\section{Late Positive Shift}

Apart from this anterior negativity for suffix replacements, there was also an increased positive activation at right electrode sites for incorrect suffixes starting around $900 \mathrm{msec}$ and lasting approximately $300 \mathrm{msec}$. An ANOVA for the time window 900-1200 msec with the factors suffix replacement, existence, and quadrant showed, apart from a main effect of quadrant $[F(3,93)=19.7, p<.001$, partial $\left.\eta^{2}=.389\right]$, a main effect of existence $[F(1,31)=$ $24.3, p<.001]$, reflecting the same widespread negativity for novel compounds that we had already seen in the 400-700 msec window. There were also significant interactions of Suffix replacement $\times$ Quadrant $[F(3,93)=$ 6.4, $p=.003$, partial $\left.\eta^{2}=.171\right]$ and a tendency of a Suffix replacement $\times$ Quadrant $\times$ Existence interaction $\left[F(3,93)=3.0, p=.058\right.$, partial $\left.\eta^{2}=.089\right]$, suggesting that the replacement of suffixes might not have led to the same effect for existing and novel compounds. We will discuss separate analyses for existing and novel compounds below.

\section{Existing Compounds}

For existing compounds, we were interested whether suffix replacement led to the same effects as interfix replacement. We therefore conducted ANOVAs for our two time windows with the factors suffix replacement (correct vs. incorrect) and interfix replacement (correct vs. replaced). Figure 2 shows ERP waveforms for a subset of the electrodes for existing compounds in the four conditions.

\section{Left Anterior Negativity}

As we were interested in anterior effects for the 400700 msec window, we restricted our analysis to the two frontal quadrants and included the factor Quadrant (anterior left vs. anterior right) into the ANOVA. The results revealed, a main effect of interfix replacement 
Figure 2. Grand-average ERPs for a subset of nine electrodes for the four conditions of existing compounds (correct compounds, incorrect interfixes, incorrect suffixes, and the combination of incorrect interfixes and suffixes). Arrows mark anterior negativity for suffix and interfix replacement as well as posterior positivity for interfix replacement.
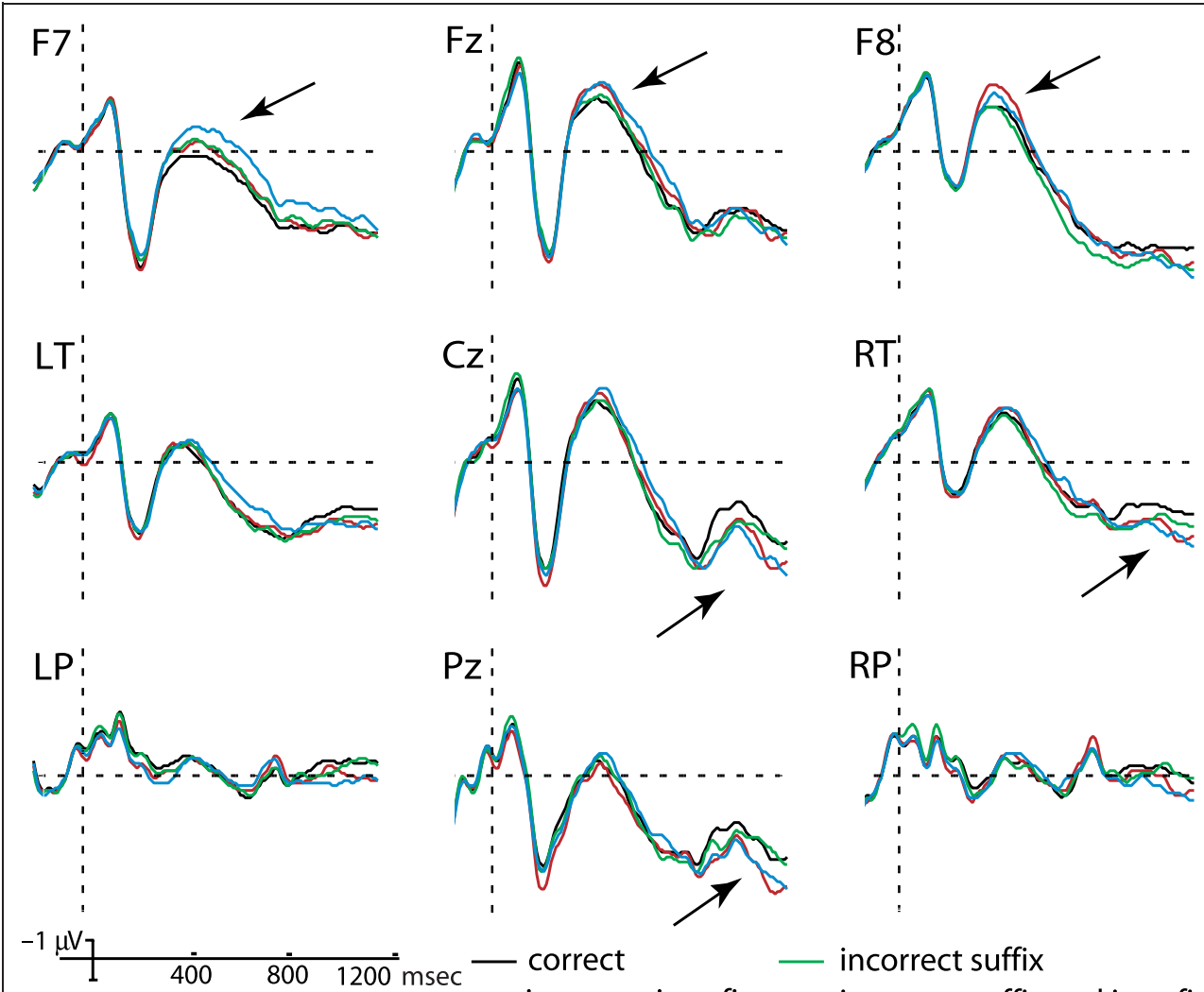

$\mathrm{Pz}$

RP'
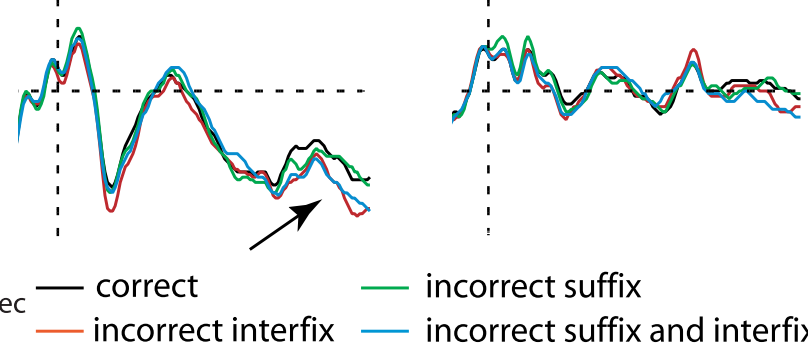

incorrect suffix incorrect suffix and interfix
$[F(1,31)=5.8, p=.022]$. As Figure 3 shows, replaced interfixes elicited an increased anterior negativity with a center at midfrontal sites. Furthermore, there was an interaction of Quadrant $\times$ Suffix replacement $[F(1,31)=$ $6.9, p=.013]$. The latter was due to the anterior negativity caused by incorrect suffixes that were restricted to the left anterior quadrant (see Figure 3) and that we had already seen in the omnibus analysis. Similar to the findings for plurals of existing German nouns, this negativity was strongest in F7 [correct suffix - incorrect suffix $=-0.6 \mu \mathrm{V}, t(31)=2.7, p=.005$, one-tailed $]$. No other effects of the ANOVA were significant (all $F_{\mathrm{S}}<1$ ).

As is visible in Figure 3, in the 400-700 msec time window the effect of the combined suffix and interfix replacement is larger than the single suffix and interfix replacement effects. Moreover, the distributions of the negativities caused by interfix replacement, suffix replacement, and the combined interfix/suffix replacement are all maximal over frontal sites with a left hemisphere preponderance. This suggests that the suffix and interfix effects might be generated by overlapping neuronal sources. If that is indeed the case, then the distinction between rule processes and analogy processes seems to be quantitative rather than qualitative, which is in accordance with single-route accounts (e.g., Joanisse \& Seidenberg, 1999; Rumelhart \& McClelland, 1986; e.g., Seidenberg \& Joanisse, 2003) and Pothos' (2005, p. 1) hypothesis that rule and analogy processes differ only in terms of the number of features involved.

\section{Late Positive Shift}

The omnibus analysis of the 900-1200 msec window had indicated that the replacement of suffixes might have led to different effects for novel and existing compounds in this time window. An ANOVA for existing compounds with the factors suffix replacement, interfix replacement, and quadrant resulted in a main effect of quadrant $\left[F(3,93)=19.2, p<.001\right.$, partial $\left.\eta^{2}=.383\right]$ and a marginally significant interaction of Quadrant $\times$ Interfix replacement $\left[F(3,93)=2.6, p=.079\right.$, partial $\left.\eta^{2}=.078\right]$, due to a posterior increased positive activation for replaced interfixes. There were no other effects (all $F$ s $<1)$. Figure 4 shows that the increased posterior positivity has its maximum over midline sites. Paired $t$ tests confirmed the significance of this effect at $\mathrm{Cz}$ $[t(31)=-2.1, p=.040]$ and Pz $[t(31)=-2.5, p=.020]$.

\section{Novel Compounds}

Having seen that the replacement of both plural suffixes and interfixes in existing compounds led to a (left) anterior negativity, we tested whether this negativity 
Figure 3. Grand-average ERPs for the left anterior electrode F7 and isovoltage maps (400-700 msec) showing (left) anterior negativities caused by the replacement of plural suffixes and interfixes in existing compounds. Note that waveforms for conditions "incorrect suffix" and "incorrect interfix" mostly overlap.

Figure 4. Isovoltage maps (900-1200 msec) showing a positive shift at posterior midline electrodes for existing compounds and a posterior positive shift for the replacement of plural suffixes in novel compounds. The increased anterior negativity for incorrect plural suffixes in novel compounds is not significant.
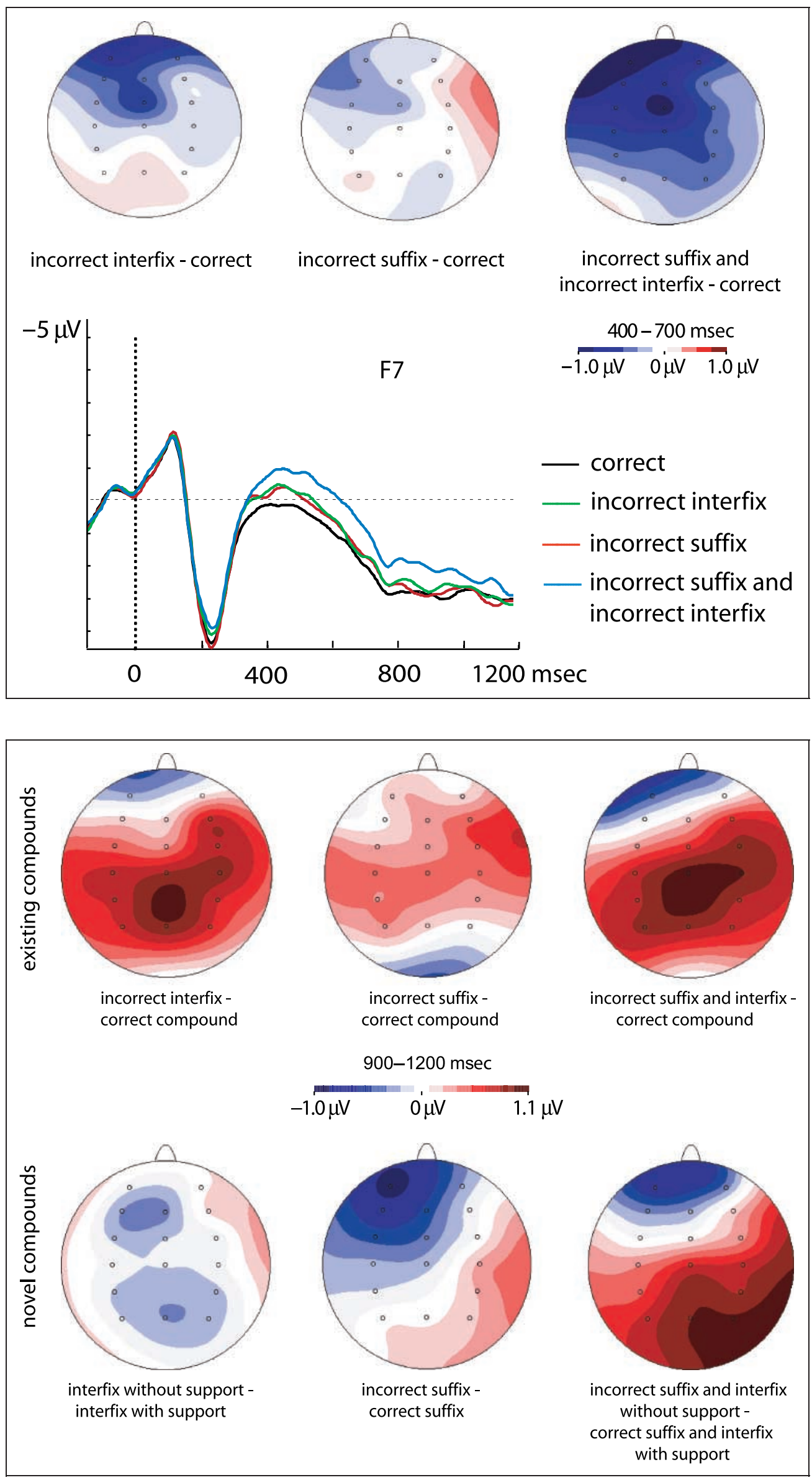
might have been caused purely by analogical support. For that we examined the effect when manipulating the support of interfixes in novel compounds. In contrast to existing compounds, for which support is confounded with correctness in our experiment, novel compounds enable us to investigate the effect of pure analogical support. Figures 5 and 6 suggest that the lack of such a support does NOT seem to lead to a negativity. This was confirmed in an ANOVA for the 400-700 msec window with the factors suffix replacement (correct vs. incorrect), interfix support (with support vs. without support), and quadrant (anterior left vs. anterior right), thus restricting our analysis to the two anterior quadrants. The results only revealed a significant interaction of Suffix replacement $\times$ Quadrant $[F(1,31)=14.3$, $p<.001]$. This interaction was due to a LAN for incorrect suffixes as shown in Figure 6, with the biggest amplitude difference over $\mathrm{F} 7[-0.7 \mu \mathrm{V}, t(31)=3.5$, $p<.001$, one-tailed]. In line with the visual impression of Figure 6, there was no significant effect of interfix support, nor any interaction of interfix support with other factors (all $F \mathrm{~S}<1$ ). Thus, although the replacement of interfixes led to an anterior negativity for existing compounds, the manipulation of the interfix support in novel compounds did not. Therefore, we can rule out that the (left) anterior negativities elicited by the replacement of both plural suffixes and interfixes were caused by the lack of analogical support of the replaced affixes.

\section{Late Positive Shift}

In contrast to existing compounds and in line with results of the omnibus analysis, Figure 5 shows that suffix replacement did have an effect for novel compounds in the 900-1200 msec window. An ANOVA with the factors suffix replacement, interfix support, and quadrant resulted in a main effect of quadrant $[F(3,93)=19.0$, $p<.001$, partial $\left.\eta^{2}=.380\right]$ and a Quadrant $\times$ Suffix replacement interaction $[F(3,93)=8.3, p=.001$, partial $\left.\eta^{2}=.211\right]$. Post hoc analyses of the quadrants showed a significantly more positive effect for incorrect suffixes in the right posterior quadrant $[t(31)=-3.8, p=.001$, two-tailed, Bonferroni-adjusted $\alpha$-level $=.0125]$. There were no other effects (all $F$ s $<1$ ).

\section{DISCUSSION}

The purpose of this study was to achieve a better understanding of the functional nature of LAN effects, in particular, of anterior negativities that had been elicited by the replacement of irregular affixes with regular affixes. More precisely, the study's aim was to test three possible causes for this negativity, namely, the misapplication of rules, the mismatch of the presented words to stored representations, and the mismatch of the presented words with an analogy-driven expectation. We chose to examine ERPs during the processing of replaced interfixes in Dutch noun-noun compounds because interfixes allowed us to manipulate the expectancy of affixes in words that are not stored and to check for analogical effects. We also manipulated the correctness of the plural suffix of the compounds to directly compare the effects of the replacement of stored affixes with the replacement of affixes governed by rules. The results of our experiment showed that replacing suffixes and interfixes in existing compounds both led to anterior negativities, which were restricted to the left hemisphere in case of suffix replacement. The results are compatible with the hypothesis that the negativities for interfixes and suffixes stem from overlapping neuronal sources. Because interfixes have been shown NOT to be governed by rules, the negativity cannot be explained by the misapplication of traditional morphological rules. Given the results for existing compounds, it can be explained either by the mismatch of the presented compounds with stored compounds or by the mismatch of the presented form with an expected form that is based on analogy to similar stored compounds. If it was the analogical support that caused the negativity, though, it should have been present also for novel compounds. That was, however, not the case. The most plausible explanation for the observed anterior negativity therefore is a mismatch of the stimuli with stored compound representations. Because of the similarity of the manipulations for plural suffixes and interfixes, namely, the replacement of two types of morphemes in otherwise identical stimuli, the most parsimonious conclusion is that both manipulations were caused by a mismatch of the stimuli with stored compound representations. This renders the suggested interpretation of the negativity in earlier studies, namely, as a misapplication of morphological rules, rather unlikely. Our explanation is also in accordance with Penke et al.'s (1997) finding that German nonce verbs did not result in different ERPs when presented with regular or irregular affixes. Because nonce verbs are not stored, they cannot clash with a stored representation.

It might be argued that the absence of an effect of analogical support for novel compounds was due to a lack of power in the materials to show such an effect. However, the experimental items used in the present study revealed an effect of analogical support in a wellformedness decision task (Krott et al., 2004). Interfixes with analogical support of the constituent family were accepted more often and faster as being well-formed than interfixes without such support. It is equally unlikely that the absence of an effect of interfix support was due to weaker attention to the novel compounds than to the existing compounds. If that was the case, we should not have been able to detect an effect for suffix replacement or an increased $\mathrm{N} 400$ component for novel compounds. Thus, although analogical support appears 
Figure 5. Grand-average ERPs for a subset of nine electrodes for the four conditions of novel compounds (correct compounds, interfixes without a combination of interfixes without support and incorrect suffixes). Pointers mark left anterior negativity and right posterior positivity for suffix replacement. support, incorrect suffixes, and

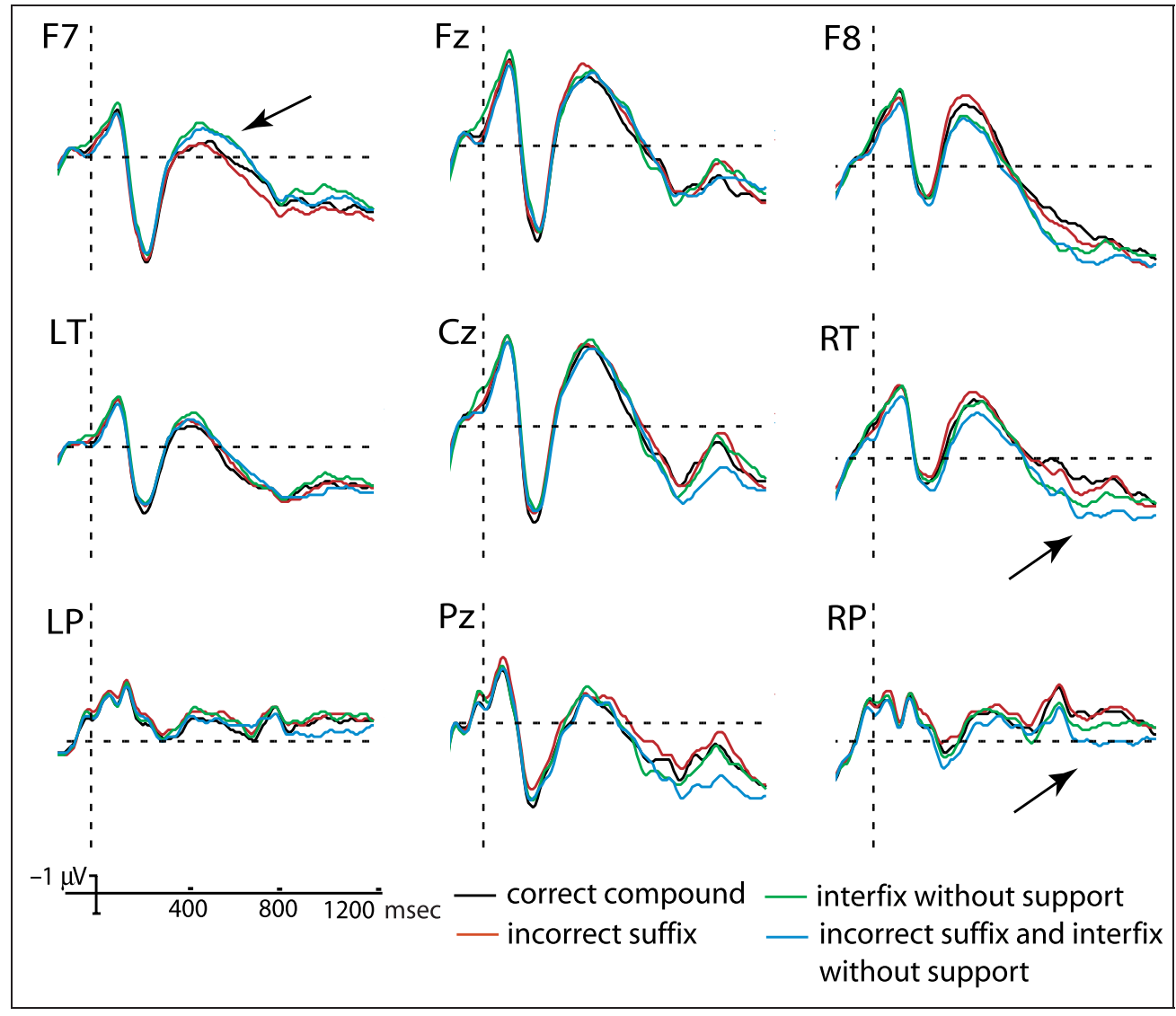

Figure 6. Grand-average ERPs for the left anterior electrode F7 and isovoltage maps (400-700 msec) showing an anterior negativity for suffix replacement and no such effect for analogy-based interfix support in novel compounds.

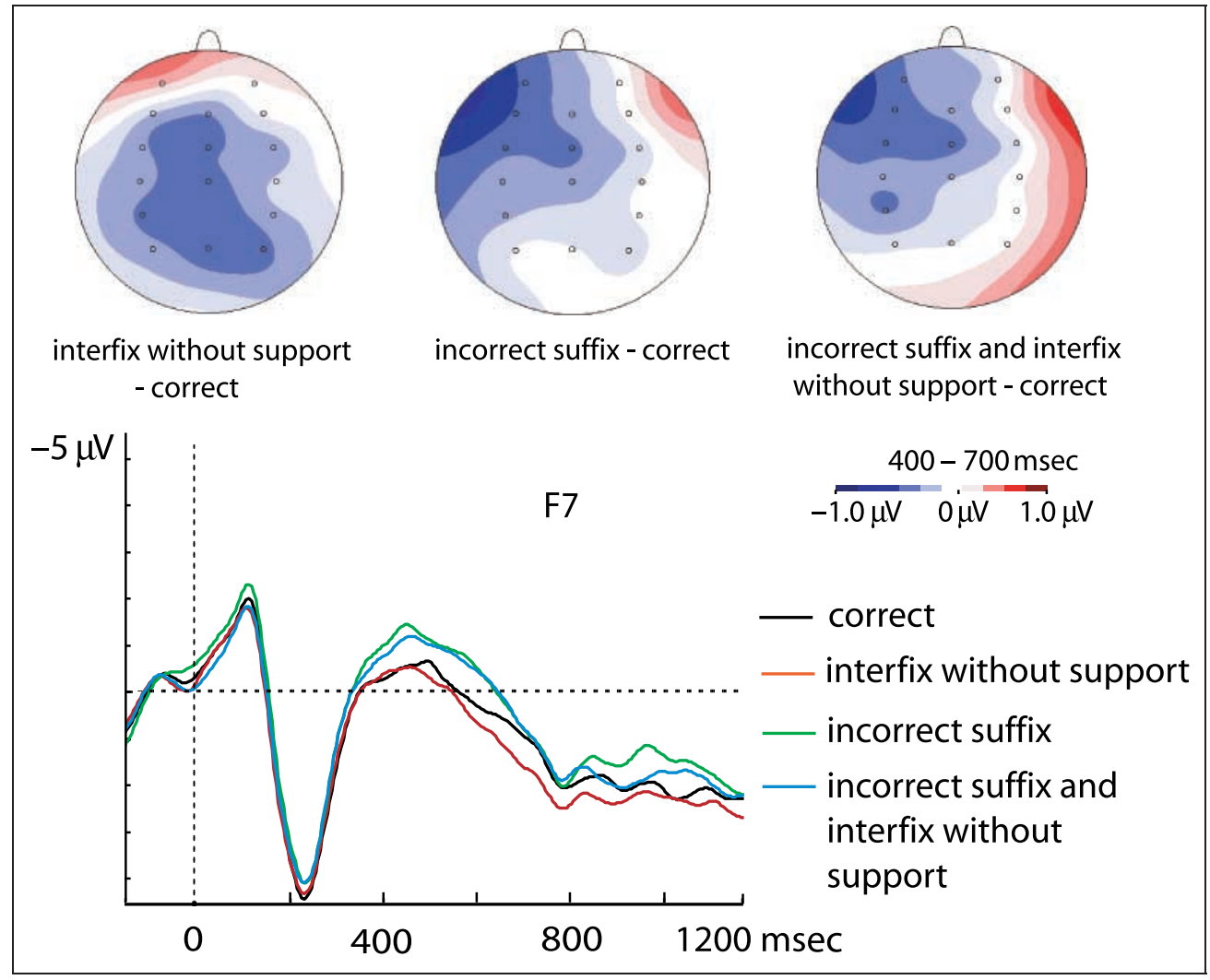


to play a role in lexical processing/well-formedness decisions, our results suggest that analogical support does not lead to anterior negativity.

The negativity caused by the replacement of suffixes had been rather small (both in terms of amplitude difference and spread), especially in the case of existing compounds. Negativities found in previous studies had been stronger (Rodriguez-Fornells et al., 2001; Gross et al., 1998; Penke et al., 1997; Weyerts et al., 1997). This difference is, however, not so surprising when one considers that, unlike in previous studies, anterior negativities were elicited by the manipulation of regular plurals, not of irregular plurals. In contrast to irregular plurals that are always stored in the mental lexicon, only a part of our regular plurals might be stored as full forms in the lexicons of our participants. If so, not all incorrect plurals clashed with a stored form, and thus, did cause a negativity, which resulted in an overall reduced effect.

Apart from anterior negativities, the results also revealed a late posterior positive shift for the replacement of suffixes in novel compounds (between 900 and $1100 \mathrm{msec}$ ) and a late posterior positive shift for the replacement of interfixes in existing compounds (between 900 and $1200 \mathrm{msec}$ ). Late positive shifts (P600/SPS) had been caused in other studies by syntactic violations (Ainsworth-Darnell, Shulman, \& Boland, 1998; Coulson et al., 1998; Friederici et al., 1996; Osterhout et al., 1994; Hagoort et al., 1993; Osterhout \& Holcomb, 1992), such as subject-verb agreement violations (e.g., Hagoort et al., 1993). A late positive shift also appeared when Catalan stem vowels of irregular verbs had been replaced by regular stem vowels (Rodriguez-Fornells et al., 2001). The cause of the positive shift for suffix replacement in novel compounds opposed to existing compounds in the present study might be due to an increased structural decomposition and/or composition of the novel combinations. Existing compounds are stored in the mental lexicon and can easily be detected as being incorrect, whereas novel compounds have to be decomposed into their constituents.

Another interesting result of our study is the widespread long-lasting negativity that we have found for novel compounds when compared to existing compounds. To our knowledge, no study to date has compared existing words with novel legal morpheme combinations. The elicited negativity resembles the increased N400 component that has been found for words that are more difficult to be integrated into context (e.g., He spread his warm bread with socks; Kutas \& Hillyard, 1980) than words that are easily integrated (e.g., He spread his warm bread with butter). The N400 effect has been shown for different types of contexts: sentences, discourses, and single words (e.g., van Berkum, Zwisterlood, Hagoort, \& Brown, 2003; Ainsworth-Darnell et al., 1998; Osterhout \& Holcomb, 1992; Holcomb, 1988; Bentin, 1987; Bentin et al., 1985; Kutas \& Hillyard, 1980; for overview articles, see
Osterhout \& Holcomb, 1995; Kutas \& Van Petten, 1994). Importantly, there is evidence that the N400 component is sensitive to word frequency and lexical status. Lowerfrequency words have been shown to lead to a more negative N400 component than higher-frequency words (Barber, Vergara, \& Carreiras, 2004; Van Petten \& Kutas, 1990). Because novel compounds have a frequency of zero, they should and do elicit a more negative N400 component. With respect to lexical status, isolated nonwords that follow the rules of English orthography and phonology have been shown to elicit a larger N400 component than existing words (Bentin, 1987; but see Nobre \& McCarthy, 1994; for orthographically illegal pseudowords, see Rugg, 1987). Bentin interprets the difference between words and nonwords as being related to word recognition, such as stimulus identification and lexical access. Like phonologically legal nonwords, novel compounds are not represented in the mental lexicon and therefore request more complex processes than existing compounds, both in terms of access and semantic processing. An increased N400 component for novel compounds might therefore reflect an increased processing demand with respect to lexical access and/or semantic interpretation. However, because left constituents of existing and novel compounds had not been matched for frequency, it is possible that part of the negativity is caused by the lower frequency for left constituents in novel compounds. Note, though, that there is plenty of evidence for full-form storage as well as for full-form access of visually presented compound words (e.g., Libben, Gibson, Yoon, \& Sandra, 2003; De Jong, Feldman, Schreuder, Pastizzo, \& Baayen, 2002). This makes it unlikely that the increased N400 component for novel compounds is entirely due to their lowerfrequency left constituent.

With regards to the debate whether morphologically complex words are better accounted for by a single- or dual-route model or whether rules and analogy processes are extremes on a continuum differing in terms of number of features involved, our results are inconclusive. Although anterior negativities were caused by misapplications of rules and by mismatch with expectations derived from similarity/analogy to stored words when manipulating existing words, our findings suggest that the true cause for LANs lies somewhere different. The manipulation of an affix only led to a LAN when an existing form was manipulated. It therefore seems to be rather the partial mismatch of a morphologically complex form with a stored form that causes the effect. The most parsimonious conclusion therefore is that anterior negativities elicited by morphological manipulations seem not to be related to morphological rules or analogy at all. It is therefore doubtful that LANs can provide valid evidence for the double dissociation between symbolic rules and associative storage assumed by dual-route models (Bartke et al., 2005; Ullman, 2004; Ullman, Bergida, \& O’Craven, 1997). 
As mentioned, LAN effects that have been caused by replacements of affixes in this and other studies closely resemble LANs elicited by syntactic violations (Coulson et al., 1998; Friederici et al., 1996; Münte et al., 1993). We have also mentioned that LAN effects might rather be a family of effects, not so much a single type of effect. Our study supports this suggestion, as the cause of the negativities identified in the present study is not compatible with syntactic LAN effects. These effects cannot be explained by a mismatch with stored sentences. Morphologically caused negativities and other LAN effects can therefore at most be viewed as different subsets of LAN effects, with the former most likely being caused by the mismatch of presented words with stored representations in the mental lexicon.

\section{Acknowledgments}

This research was financially supported by the Dutch National Research Council NWO (PIONIER grant to the second author), the Radboud University Nijmegen (The Netherlands), and the Max Planck Institute for Psycholinguistics (Nijmegen, The Netherlands). We thank Marijn Knops for his help with collecting and processing the data and two anonymous reviewers for their helpful comments.

Reprint requests should be sent to Andrea Krott, School of Psychology, University of Birmingham, Edgbaston, Birmingham B15 2TT, UK, or via e-mail: a.krott@bham.ac.uk.

\section{Notes}

1. Note that we follow the terminology of Marcus, Brinkman, Clahsen, Wiese, and Pinker (1995) without committing ourselves to the view that $-(e) n$ is indeed irregular nor that $-s$ is a paradigm case of regularity. The superiority of the dual-route approach for German noun inflection and/or the claim that only the $-s$ plural is predictable have been questioned (Bartke, Rösler, Streb, \& Wiese, 2005; Hahn \& Nakisa, 2000; Dressler, 1999; Indefrey, 1999; Köpcke, 1998).

2. Note that both interfixes $-e n-$ and $-s$ - are homographic to the two Dutch nominal plural suffixes. Interfixes are, however, not merely plural suffixes because they often appear with stems that take other plural suffixes (e.g., the plural of schaap "sheep" is schaap + en, while it occurs with $-s-$ in schaap + $s+$ leder "sheep leather"). Nevertheless, Dutch interfixes can induce plural interpretation of the left constituent (Schreuder, Neijt, van der Weide, \& Baayen, 1998), in contrast to results for German interfixes (Köster et al., 2004).

3. Note that we treat compounds without overt interfixes (e.g., kamer $+\varnothing+$ meid "chamber maid") as containing an empty interfix $-\varnothing$-, based on results of previous studies (Krott, Krebbers, et al., 2002; Krott, Schreuder, et al., 2002a, 2002b; Krott, et al., 2001), which showed that $\varnothing_{-}$is affected by analogy just like $-e n-$ and $-s-$.

\section{REFERENCES}

Ainsworth-Darnell, K., Shulman, H. G., \& Boland, J. E. (1998). Dissociating brain responses to syntactic and semantic anomalies: Evidence from event-related potentials. Journal of Memory and Language, 38, 112-130.
Albright, A., \& Hayes, B. (2003). Rules vs. Analogy in English past tenses: A computational/experimental study. Cognition, 90, 119-161.

Alegre, M., \& Gordon, P. (1999). Frequency effects and the representational status of regular inflections. Journal of Memory and Language, 40, 41-61.

Baayen, R. H., Dijkstra, T., \& Schreuder, R. (1997). Singulars and plurals in Dutch: Evidence for a parallel dual-route modes. Journal of Memory and Language, 37, 94-117.

Baayen, R. H., \& Martin, F. M. D. (2005). Semantic density and past-tense formation in three Germanic languages. Language, 81, 666-698.

Baayen, R. H., Piepenbrock, R., \& Gullikers, L. (1995). The CELEX lexical database [CD-ROM]. Philadelphia, PA: Linguistics Data Consortium, University of Pennsylvania.

Baayen, R. H., Schreuder, R., De Jong, N. H., \& Krott, A. (2002). Dutch inflection: The rules that prove the exception. In S. Nooteboom, F. Weerman, \& F. Wijnen (Eds.), Storage and computation in the language faculty (pp. 61-92). Dordrecht: Kluwer Academic Publishing.

Barber, H., Vergara, M., \& Carreiras, M. (2004). Syllablefrequency effects in visual word recognition: Evidence from ERPs. NeuroReport, 15, 545-548.

Bartke, S., Rösler, F., Streb, J., \& Wiese, R. (2005). An ERP-study of German "irregular" morphology. Journal of Neurolinguistics, 18, 29-55.

Bentin, S. (1987). Event-related potentials, semantic processes, and expectancy factors in word recognition. Brain and Language, 31, 308-327.

Bentin, S., McCarthy, G., \& Wood, C. C. (1985). Event-related potentials, lexical decision and semantic priming. Electroencephalography and Clinical Neurophysiology, 60, 343-355.

Bertram, R., Laine, M., Baayen, R. H., Schreuder, R., \& Hyona, J. (2000). Affixal homonymy triggers full-form storage, even with inflected words, even in a morphologically rich language. Cognition, 74, B13-B25.

Bird, H., Ralph, M. A. L., Seidenberg, M. S., McClelland, J. L., \& Patterson, K. (2003). Deficits in phonology and past-tense morphology: What's the connection? Journal of Memory and Language, 48, 502-526.

Braber, N., Patterson, K., Ellis, K., \& Ralph, M. A. L. (2005). The relationship between phonological and morphological deficits in Broca's aphasia: Further evidence from errors in verb inflection. Brain and Language, 92, 278-287.

Bybee, J. L., \& Moder, C. L. (1983). Morphological classes as natural categories. Language, 59, 251-270.

Bybee, J. L., \& Slobin, D. I. (1982). Rules and schemas in the development and use of the English past tense. Language, 58, 265-289.

Coulson, S., King, J. W., \& Kutas, M. (1998). Expect the unexpected: Event-related brain response to morphosyntactic violations. Language and Cognitive Processes, 13, 21-58.

De Jong, N. H., Feldman, L. B., Schreuder, R., Pastizzo, M., \& Baayen, R. H. (2002). The processing and representation of Dutch and English compounds: Peripheral morphological and central orthographic effects. Brain and Language, 81, 555-567.

Deacon, D., Dynowska, A., Ritter, W., \& Grose-Fifer, J. (2004). Repetition and semantic priming of nonwords: Implications for theories of $\mathrm{N} 400$ and word recognition. Psychophysiology, 41, 60-74.

Dressler, W. U. (1999). Why collapse morphological concepts? Behavioral and Brain Sciences, 22, 1021.

Friederici, A. D. (1995). The time-course of syntactic activation during language processing-A model-based on neuropsychological and neurophysiological data. Brain and Language, 50, 259-281. 
Friederici, A. D., Gunter, T. C., Hahne, A., \& Mauth, K. (2004). The relative timing of syntactic and semantic processes in sentence comprehension. NeuroReport, 15, 165-169.

Friederici, A. D., Hahne, A., \& Mecklinger, A. (1996). Temporal structure of syntactic parsing: Early and late event-related brain potential effects. Journal of Experimental Psychology: Learning, Memory, and Cognition, 22, 1219-1248.

Friederici, A. D., Pfeifer, E., \& Hahne, A. (1993). Event-related brain potentials during natural speech processing-Effects of semantic, morphological and syntactic violations. Cognitive Brain Research, 1, 183-192.

Gross, M., Say, T., Kleingers, M., Clahsen, H., \& Münte, T. F. (1998). Human brain potentials to violations in morphologically complex Italian words. Neuroscience Letters, 241, 83-86.

Hagoort, P., Brown, C., \& Groothusen, J. (1993). The syntactic positive shift (SPS) as an ERP measure of syntactic processing. Language and Cognitive Processes, 8, 439-483.

Hagoort, P., Wassenaar, M., \& Brown, C. A. (2003). Syntax-related ERP-effects in Dutch. Cognitive Brain Research, 16, 38-50.

Hahn, U., \& Nakisa, R. C. (2000). German inflection: Single route or dual route? Cognitive Psychology, 41, 313-360.

Holcomb, P. J. (1988). Automatic and attentional processingAn event-related brain potential analysis of semantic priming. Brain and Language, 35, 66-85.

Indefrey, P. (1999). Some problems with the lexical status of nondefault inflection. Behavioral and Brain Sciences, 22, 1025 .

Joanisse, M. F., \& Seidenberg, M. S. (1999). Impairments in verb morphology after brain injury: A connectionist model. Proceedings of the National Academy of Sciences, U.S.A., 96, 7592-7597.

Kluender, R., \& Kutas, M. (1993a). Bridging the gap-Evidence from ERPs on the processing of unbounded dependencies. Journal of Cognitive Neuroscience, 5, 196-214.

Kluender, R., \& Kutas, M. (1993b). Subjacency as a processing phenomenon. Language and Cognitive Processes, 8, 573-633.

Krott, A., Baayen, R. H., \& Schreuder, R. (2001). Analogy in morphology: Modeling the choice of linking morphemes in Dutch. Linguistics, 39, 51-93.

Krott, A., Hagoort, P., \& Baayen, R. H. (2004). Sublexical units and supralexical combinatorics in the processing of interfixed Dutch compounds. Language and Cognitive Processes, 19, 453-471.

Krott, A., Krebbers, L., Schreuder, R., \& Baayen, R. H. (2002). Semantic influence on linkers in Dutch noun-noun compounds. Folia Linguistica, 36, 7-22.

Krott, A., Schreuder, R., \& Bayyen, R. H. (2002a). Analogical hierarchy: Examplar-based modeling of linkers in Dutch noun-noun compounds. In R. Skousen, D. Londsdale, \& D. B. Parkinson (Eds.), Analogical modeling: An examplar-based approach to language (pp. 181-206). Amsterdam: John Benjamins.

Krott, A., Schreuder, R., \& Baayen, R. H. (2002b). Linking elements in Dutch noun-noun compounds: Constituent families as analogical predictors for response latencies. Brain and Language, 81, 723-735.

Kutas, M., \& Hillyard, S. A. (1980). Reading senseless sentences-Brain potentials reflect semantic incongruity. Science, 207, 203-205.

Kutas, M., \& Van Petten, C. K. (1994). Psycholinguistics electrified: Event-related brain potential investigations. In M. A. Gernsbacher (Ed.), Handbook of psycholinguistics (pp. 83-143). San Diego: Academic Press.
Köpcke, K. M. (1998). The acquisition of plural marking in English and German revisited: Schemata versus rules. Journal of Child Language, 25, 293-319.

Köster, D., Gunter, T. C., Wagner, S., \& Friederici, A. D. (2004). Morphosyntax, prosody, and linking elements: The auditory processing of German nominal compounds. Journal of Cognitive Neuroscience, 16, 1647-1668.

Libben, G., Gibson, M., Yoon, Y. B., \& Sandra, D. (2003). Compound fracture: The role of semantic transparency and morphological headedness. Brain and Language, $84,50-64$.

Marcus, G. F., Brinkman, U., Clahsen, H., Wiese, R., \& Pinker, S. (1995). German inflection: The exception that proves the rule. Cognitive Psychology, 29, 189-256.

Marslen-Wilson, W., \& Tyler, L. K. (1998). Rules, representations, and the English past tense. Trends in Cognitive Sciences, 2, 428-435.

Marslen-Wilson, W., \& Tyler, L. K. (2003). Capturing underlying differentiation in the human language system. Trends in Cognitive Sciences, 7, 62-63.

Mattens, W. H. M. (1984). De voorspelbaarheid van tussenklanken in nominale samenstellingen [The predictability of linking phonemes in nominal compounds]. De Nieuwe Taalgids, 7, 333-343.

Miozzo, M. (2003). On the processing of regular and irregular forms of verbs and nouns: Evidence from neuropsychology. Cognition, 87, 101-127.

Münte, T. F., \& Heinze, H. J. (1994). ERP negativities during syntactic processing of written words. In H. J. Heinze, T. F. Münte, \& G. R. Mangun (Eds.), Cognitive electrophysiology. Boston, MA: Birkhäuser.

Münte, T. F., Heinze, H. J., \& Mangun, G. R. (1993). Dissociation of brain activity related to syntactic and semantic aspects of language. Journal of Cognitive Neuroscience, 5, 335-344.

Neville, H., Nicol, J. L., Barss, A., Forster, K. I., \& Garrett, M. F. (1991). Syntactically based sentence processing classes-Evidence from event-related brain potentials. Journal of Cognitive Neuroscience, 3, 151-165.

New, B., Brysbaert, M., Segui, J., Ferrand, L., \& Rastle, K. (2004). The processing of singular and plural nouns in French and English. Journal of Memory and Language, 51, 568-585.

Nobre, A. C., \& McCarthy, G. (1994). Language-related ERPs-Scalp distributions and modulation by word type and semantic priming. Journal of Cognitive Neuroscience, 6, 233-255.

Oldfield, R. C. (1971). The assessment and analysis of handedness: The Edinburgh Inventory. Neuropsychologia, 9, 97-113.

Osterhout, L., \& Holcomb, P. J. (1992). Event-related brain potentials elicited by syntactic anomaly. Journal of Memory and Language, 31, 785-806.

Osterhout, L., \& Holcomb, P. J. (1995). Event-related potentials and language comprehension. In M. D. Rugg \& M. G. H. Coles (Eds.), Electrophysiology of mind (pp. 171-215). Oxford, UK: Oxford University Press.

Osterhout, L., Holcomb, P. J., \& Swinney, D. A. (1994). Brain potentials elicited by garden-path sentencesEvidence of the application of verb information during parsing. Journal of Experimental Psychology: Learning, Memory, and Cognition, 20, 786-803.

Palolahti, M., Leino, S., Jokela, M., Kopra, K., \& Paavilainen, P. (2005). Event-related potentials suggest early interaction between syntax and semantics during on-line sentence comprehension. Neuroscience Letters, 384, 222-227.

Patterson, K., Ralph, M. A. L., Hodges, J. R., \& McClelland, J. L. (2001). Deficits in irregular past-tense verb morphology 
associated with degraded semantic knowledge. Neuropsychologia, 39, 709-724.

Penke, M., Weyerts, H., Gross, M., Zander, E., Münte, T. F., \& Clahsen, H. (1997). How the brain processes complex words: An event-related potential study of German verb inflections. Cognitive Brain Research, 6, 37-52.

Pinker, S. (1999). Words and rules: The ingredients of language. New York: Basic Books.

Pinker, S., \& Ullman, M. T. (2002). The past and future of the past tense. Trends in Cognitive Sciences, 6, 456-463.

Pothos, E. M. (2005). The rules versus similarity distinction. Behavioral and Brain Sciences, 28, 1-14.

Ralph, M. A. L., Braber, N., McClelland, J. L., \& Patterson, K. (2005). What underlies the neuropsychological pattern of irregular > regular past-tense verb production? Brain and Language, 93, 106-119.

Rodriguez-Fornells, A., Clahsen, H., Lleo, C., Zaake, W., \& Münte, T. F. (2001). Event-related brain responses to morphological violations in Catalan. Cognitive Brain Research, 11, 47-58.

Rossi, S., Gugler, M. F., Hahne, A., \& Friederici, A. D. (2005). When word category information encounters morphosyntax: An ERP study. Neuroscience Letters, 384, 228-233.

Rugg, M. D. (1987). Dissociation of semantic priming, word and non-word repetition effects by event-related potentials. Quarterly Journal of Experimental Psychology, Series A, Human Experimental Psychology, 39, 123-148.

Rugg, M. D., \& Nagy, M. E. (1987). Lexical contribution to nonword-repetition effects-Evidence from event-related potentials. Memory \& Cognition, 15, 473-481.

Rumelhart, D. E., \& McClelland, J. L. (1986). On learning the past tenses of English verbs. In J. L. McClelland \& D. E. Rumelhart (Eds.), Parallel distributed processing: Explorations in the microstructures of cognition (Vol. 2, pp. 216-271). Cambridge: MIT Press.

Rösler, F., Putz, P., Friederici, A., \& Hahne, A. (1993). Event-related brain potentials while encountering semantic and syntactic constraint violations. Journal of Cognitive Neuroscience, 5, 345-362.

Schreuder, R., de Jong, N., Krott, A., \& Baayen, R. H. (1999). Rules and rote: Beyond the linguistic either-or fallacy. Behavioral and Brain Sciences, 22, 1038-1039.

Schreuder, R., Neijt, A., van der Weide, F., \& Baayen, R. H. (1998). Regular plurals in Dutch compounds: Linking graphemes or morphemes? Language and Cognitive Processes, 13, 551-573.
Seidenberg, M. S., \& Joanisse, M. F. (2003). Show us the model. Trends in Cognitive Sciences, 7, 106-107.

Sereno, J. A., \& Jongman, A. (1997). Processing of English inflectional morphology. Memory \& Cognition, 25 , 425-437.

Tyler, L. K., Randall, B., \& Marslen-Wilson, W. D. (2002). Phonology and neuropsychology of the English past tense. Neuropsychologia, 40, 1154-1166.

Ullman, M. T. (1999). Acceptability ratings of regular and irregular past-tense forms: Evidence for a dual-system model of language from word frequency and phonological neighbourhood effects. Language and Cognitive Processes, 14, 47-67.

Ullman, M. T. (2001). A neurocognitive perspective on language: The declarative/procedural model. Nature Reviews Neuroscience, 2, 717-726.

Ullman, M. T. (2004). Contributions of memory circuits to language: The declarative/procedural model. Cognition, 92, 231-270.

Ullman, M. T., Bergida, R., \& O'Craven, K. M. (1997). Distinct fMRI activation patterns for regular and irregular past tense. Neuroimage, 5, S549.

van Berkum, J. J. A., Zwisterlood, P., Hagoort, P., \& Brown, C. M. (2003). When and how do listeners relate a sentence to the wider discourse? Evidence from the N400 effect. Cognitive Brain Research, 17, 701-718.

van den Toorn, M. C. (1982a). Tendenzen bij de beregeling van de verbindingsklank in nominale samenstellingen i [Tendencies for the regulation of linking phonemes in nominal compounds i]. De Nieuwe Taalgids, 75, $24-33$.

van den Toorn, M. C. (1982b). Tendenzen bij de beregeling van de verbindingsklank in nominale samenstellingen ii [tendencies for the regulation of linking phonemes in nominal compounds]. De Nieuwe Taalgids, 75, 153-160.

Van Petten, C., \& Kutas, M. (1990). Interactions between sentence context and word-frequency in event-related brain potentials. Memory \& Cognition, 18, 380-393.

Vos, S. H., Gunter, T. C., Kolk, H. H. J., \& Mulder, G. (2001). Working memory constraints on syntactic processing: An electrophysiological investigation. Psychophysiology, 38, 41-63.

Weyerts, H., Penke, M., Dohrn, U., Clahsen, H., \& Münte, T. F. (1997). Brain potentials indicate differences between regular and irregular German plurals. NeuroReport, 8, 957-962. 